University of Nebraska - Lincoln

DigitalCommons@University of Nebraska - Lincoln

USDA National Wildlife Research Center - Staff Publications
U.S. Department of Agriculture: Animal and Plant Health Inspection Service

January 2001

\title{
Design of a Laboratory Secondary Hazard Study
}

David A. Goldade

APHIS/WS/National Wildlife Research Center, U.S. Department of Agriculture

Peter J. Savarie

APHIS/WS/National Wildlife Research Center, U.S. Department of Agriculture

Jerome C. Hurley

APHIS/WS/National Wildlife Research Center, U.S. Department of Agriculture

Stanley A. Gaddis

APHIS/WS/National Wildlife Research Center, U.S. Department of Agriculture

John J. Johnston

APHIS/WS/National Wildlife Research Center, U.S. Department of Agriculture

Follow this and additional works at: https://digitalcommons.unl.edu/icwdm_usdanwrc

Part of the Environmental Sciences Commons

Goldade, David A.; Savarie, Peter J.; Hurley, Jerome C.; Gaddis, Stanley A.; and Johnston, John J., "Design of a Laboratory Secondary Hazard Study" (2001). USDA National Wildlife Research Center - Staff Publications. 588.

https://digitalcommons.unl.edu/icwdm_usdanwrc/588

This Article is brought to you for free and open access by the U.S. Department of Agriculture: Animal and Plant Health Inspection Service at DigitalCommons@University of Nebraska - Lincoln. It has been accepted for inclusion in USDA National Wildlife Research Center - Staff Publications by an authorized administrator of DigitalCommons@University of Nebraska - Lincoln. 
Published in Pesticides and Wildlife, edited by John J. Johnston. ACS Symposium Series 771. American Chemical Society, Washington, DC, 2001. 


\section{Chapter 11}

\section{Design of a Laboratory Secondary Hazard Study}

David A. Goldade, Peter J. Savarie, Jerome C. Hurley, Stanley A. Gaddis, and John J. Johnston

\section{APHIS/WS/National Wildlife Research Center, U.S. Department of Agriculture, 4101 La Porte Avenue, Fort Collins, CO 80521-2154}

Factors influencing the design and execution of a secondary hazard study are presented using the anticoagulant rodenticide,

difethialone, as a model. Frequently, regulatory agencies require a determination of the potential hazard posed to non-target species by the application of pesticides. This hazard can occur through: 1) primary hazard, direct consumption of the bait or formulation containing the pesticide, or 2) secondary hazard, indirect consumption of the pesticide via ingestion of biological matrices such as animals or plants containing pesticide residues. In making this determination, the selection of appropriate test species as well as routes and level of exposure are critical. For the example study of the estimation of secondary hazards associated with difethialone, albino rats served as the representative species for the primary target animal. Ferrets and magpies served as representative mammalian and avian secondary scavenger species, respectively.

\section{Introduction}

Numerous factors should be considered in the design and implementation of a secondary hazard study including biological, chemical, and agricultural influences. Careful consideration of these factors should produce sufficient data to permit informed regulatory decisions incorporating potential hazards posed by the proposed application of the pesticide. This paper addresses the consideration of these variables by presenting a secondary hazard study performed in our laboratory for the anticoagulant rodenticide, difethialone (3-[(1RS,3RS;1RS,3SR)-3-(4'-bromobiphenyl4-yl)-1,2,3,4-tetrahydro-1-naphthyl]-4-hydroxy-1-benzothi-in-2-one).

\section{Definitions}

In its broadest terms, a secondary hazard exists when there is a possibility of poisoning to secondary (or non-target) species from the consumption of the primary (or target) species. This is differentiated from a primary hazard which occurs from consumption or direct contact with the formulated pesticide. This is a generalized description which can cover many possible exposure scenarios from the aerial application of a liquid herbicide formulation for weed control to the use of a toxicant formulated as a pelleted bait to control populations of a pest animal. For difethialone, the potential primary hazard pertains to the consumption of formulated baits and the potential secondary hazard from consumption of the carcasses of the primary species containing pesticide residues. This is illustrated in Figure 1 where the cross-hatched arrows indicate routes of primary hazard and solid arrows indicate routes of secondary hazard.

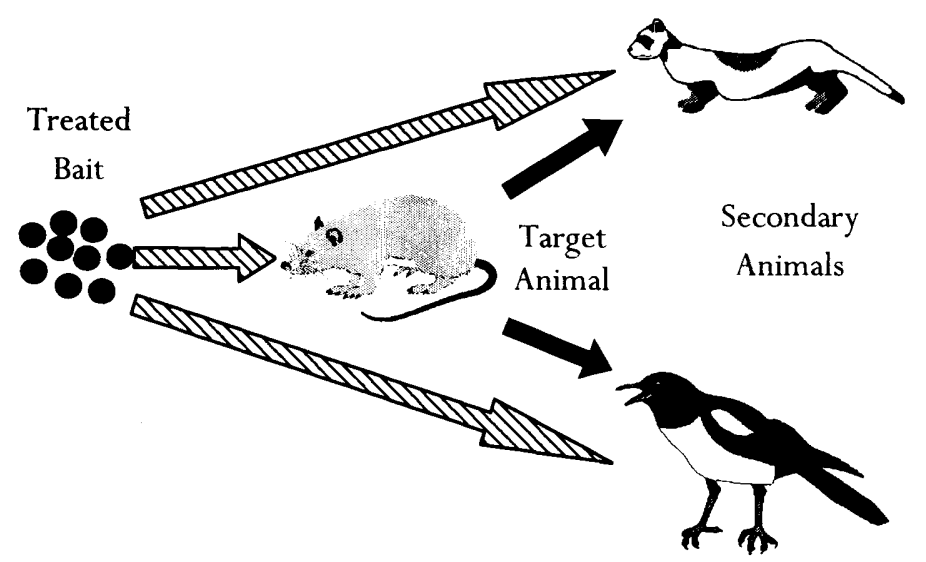

Figure 1. Primary (cross-hatched arrows) and secondary (solid arrows) hazards from a treated bait.

\section{Overview}

To approximate likely field conditions, the first step of our study was to feed the pesticide to the target species at realistic levels. Carcasses of the target species were then analyzed to determine the range of concentrations to which secondary species might be exposed. The toxicity of the pesticide to the secondary species was assessed 
by feeding a range of pesticide concentrations in a formulated diet to the secondary species. The formulated diet was meat-based to approximate the primary species carcasses containing pesticide residues. Secondary hazards were then estimated by comparing the toxicity of the pesticide to the secondary species with the pesticide residues in the target (primary) species.

\section{Toxicological Considerations}

The toxicological properties of the pesticide should be determined and subsequently considered in the design of a secondary hazard study. Of prime importance is the determination of the mode of action for the toxic agent. This can frequently be discerned by examining pathological and toxicological data about the pesticide. Determination of the organs affected can provide clues as to how the pesticide exerts its toxic effect and can provide direction in how best to determine residue levels. The elimination rate or half-life indicates how long the chemical is present in the organism, and therefore how long a potential hazard persists following exposure. The individual elimination rates for various tissue types need to be considered as well. If the pesticide is stored in adipose tissue, it is likely that whole body residues will need to be quantified. If the pesticide is preferentially stored in certain organs, then the residues in those organs should be determined.

An additional significant consideration is metabolism of the pesticide. If the chemical undergoes either detoxification or bioactivation, the fate and toxicity of the metabolites could prove to be very important. Thus, significant metabolites should be identified and the toxicity of these metabolites to the secondary species determined. If a detoxification process is occurring, the toxicity of the metabolite(s) to secondary species is probably lower than that of the parent compound. This would likely lessen the secondary hazards associated with residues of the pesticide. If bioactivation is occurring, it is likely that the metabolite(s) could produce toxic effects in the secondary species similar to those in the primary species (1).

Difethialone is an anti-vitamin $\mathrm{K}$ anticoagulant rodenticide of the chemical class hydroxy-4-benzothiopyranones. It exerts its toxic hemorrhagic effects by inhibiting the synthesis of Vitamin-K dependent blood coagulation factors. It does not cause necrosis in any specific organ, but effects the blood coagulation system throughout the body. As with most other anticoagulant rodenticides it bioaccumulates in the liver as evidenced by its long liver half-life of 108 days (2). Studies with ${ }^{14} \mathrm{C}$-labeled difethialone indicate that it does not undergo significant metabolism (2). Therefore, the toxic effects associated with exposure to this compound are due to the parent compound. Death typically occurs from internal hemorrhage following consumption of a lethal dose (1). A lethal dose can be ingested in a single feeding (acute) or may occur following repeated feedings (sub-chronic). The toxic material is applied at a low concentration and there are no immediate toxic effects observed; therefore, there is little or no bait shyness associated with the use of this compound. This serves to increase the likelihood that a lethal dose will be ingested (1).

\section{Mode of Delivery}

The method of delivery for the pesticide being evaluated in the secondary hazard study is dependent on one important factor: how exposures are likely to occur in the field. If the chemical is sprayed onto plants, the potential exists for ingestion by herbivores. If the formulation is a pelleted or grain bait, application will likely be via broadcast. To reduce potential non-target primary hazards, application procedures may be modified such as through the use of bait stations. The degree of water solubility can be important for movement of the pesticide into ground water. If it is applied as an aerosol, potential dermal exposure to non-target species should be considered. However, for the purposes of a secondary hazard study, the most important route of exposure is oral via consumption of carcasses of the primary species containing pesticide residues.

Difethialone is prepared and marketed as a $0.0025 \%$ pelleted bait and is designed for the control of rodent populations in and around structures (EPA Registration Numbers 7173-205, 7173-206, 7173-211, and 7173-218). The pelleted bait is consumed by pest rodent species whose carcasses represent the source of the secondary hazard to scavenger species. For difethialone, the principle source of primary hazard is from consumption of the treated bait. However, since it is used for control of commensal rodents, it is not as likely to be consumed by non-target wildlife species. If the bait were applied in a broadcast fashion, the likelihood of ingestion by non-target species would probably increase. Difethialone has moderate water solubility and is applied in relatively low concentrations. Therefore, potential exposure via surface water contamination should be extremely low. The largest potential secondary hazard is from consumption of the carcasses of the primary species. The primary reasons for expecting residues to be present in the primary species are the relatively long half-life of difethialone in liver and blood (108 and 2.3 days respectively (2)) and the lack of bait-shyness for the target animals. As there is no bait-shyness associated with the formulated bait, there is an increase in the likelihood of significant residues being present in the carcass of the target species as the animal will continue to feed on the bait. Since feeding studies with the pelleted bait reveal that the time to death is typically less than seven days for the primary species, the potential exists for significant residues to be present in the carcass of the primary species at the time of its death. Therefore, the mode of delivery selected for the secondary study of difethialone was via the oral route.

For our study, the primary species were fed difethialone-treated bait. Possibilities considered for dosing the secondary species were to feed 1) carcasses of the primary species fed difethialone bait, 2) homogenized primary species fortified with difethialone, or 3) a surrogate ground substrate, such as dog food, fortified with difethialone. As difethialone residues in rat carcasses were extremely variable (c.v. = $26 \%$ ), feeding carcasses of the primary species which had fed on difethialone baits would result in extremely variable and inconsistent doses to the secondary species. This would likely produce variable toxicity data that would be of little value for subsequent risk assessment. Additionally, in order to generate toxicity data (such as $\mathrm{LD}_{50}$ or $\mathrm{LC}_{50}$ values) dosing must be performed at a sufficient number of known 
doses or concentration levels in order to produce a range of percent mortality results. This means that the carcasses of the primary species would have to be fortified with additional difethialone in order to produce the mortality required to generate a doseresponse curve. Homogenization and subsequent fortification of the primary species to produce a homogeneous blend of fortified rat tissue was impractical as the study required $113 \mathrm{~kg}$ of fortified diet. The production of such a large quantity of treated diet would have involved the needless pain and suffering and subsequent deaths of nearly 600 additional rats. We chose the simpler, less expensive, more humane option of fortifying dog food with difethialone. This approach was relatively straight forward and produced a homogeneous diet for accurate delivery of the toxicant.

\section{Selection of Test Species}

The most important factor in selecting test species is to ensure they are representative of species likely to be found in a field setting. Often it is impractical to have the exact species which will be exposed, either because the species is endangered or threatened or because the species is not available from a commercial source. Likewise, it is impractical to test each and every species likely to be exposed (3). Therefore, representative species are chosen and testing conducted on them. At a minimum, the species selected should be of the same family or genus as the species found in the field. This makes extrapolation of results to other species found in the field less controversial and more reliable. The number of these animals needed for testing must be sufficient to provide statistically significant data and to provide a reasonably tight confidence interval for toxicity values (i.e. $L_{50}$ ) of the pesticide to the secondary species. However, the degree of significance will vary from chemical to chemical and study to study. For compounds and proposed uses that generate intermediate risk assessments (see section on Risk Quotients below), a fairly precise $\mathrm{LD}_{50}$ or $\mathrm{LC}_{50}$ is desired. Another factor which must be addressed is gender. In most studies both genders should be represented, particularly if both genders are likely to be exposed in the field. This approach will also help to elucidate any gender-specific metabolic processes that may be occurring.

For the primary species, albino laboratory rats (Rattus norvegicus) were chosen because they were readily available, easy to handle, and are highly representative of wild rodent species likely to be found in the field. Secondary exposures are likely to occur to both mammalian and avian scavenger and predator species which feed on the carcasses of the primary species. For the laboratory study, European ferrets (Mustela putorius furo) and black-billed magpies (Pica pica) were chosen as representative secondary species. European ferrets were chosen because they were easy to obtain and highly representative of mammalian scavengers. Black-billed magpies were chosen because they were available in the region, relatively easy to obtain, and are representative of avian scavengers. They were not, however, representative of avian raptor species. An actual raptor species was not used because the use of raptor species in lethal feeding studies is less socially acceptable than is the use of scavenger species.

\section{Level of Exposure}

The selection of a level of exposure, primary or secondary, is important to provide a realistic result to the experiment. If the level of exposure is too high or too low the resulting data will be of little utility. Above all, the exposure levels should encompass those expected to be found in the field. Primary species should be exposed to levels at or slightly greater than the maximum estimated field exposure. For secondary species, toxicity values (minimally $\mathrm{LD}_{50}$ or $\mathrm{LC}_{50}$ ) must be determined. Secondary animals need to be exposed to a range of concentration levels designed to result in both high and low percent mortality.

Literature values for residue levels of difethialone in the carcasses of rodents consuming difethialone baits were not available. Therefore, difethialone baits were fed ad libitum to rats for 3-7 days or until death occurred. Rats were frozen as soon as possible after death. The carcasses of these rodents were analyzed for residue levels of difethialone. Further, there were no literature $\mathrm{LD}_{50}$ values for either magpies or ferrets. Feeding studies with difethialone fortified dog food (a surrogate for rat tissues containing difethialone residues) were conducted to generate toxicity curves for the two secondary hazard species. These values were used to estimate $\mathrm{LD}_{50}$ values.

\section{Analytical Chemistry Requirements}

The determination of toxicant levels in the matrices chosen for the study is a critical step in the assessment of secondary hazard. To this end, sensitive and selective methods must be developed and validated for the toxicant and its metabolites as required. These methods must cover all possible matrices of interest including the treated baits, the carcasses of the primary species, and the target organs and/or carcasses of the secondary species.

Methods were developed to permit the quantification of difethialone residues in whole-body rodent carcasses, ferret and magpie liver, and dog food formulations. Briefly, the methods employed a dual retention solid phase extraction procedure with high-performance liquid chromatography separation and ultra violet detection $(4,5)$. For each matrix a method limit of detection (MLOD) was determined. Each matrix was fortified at a range of concentrations and the percent recovery determined for each. The MLOD, validated range, and mean and standard deviation for the recoveries are given in Table I. These values demonstrate that the methods developed were sufficiently sensitive, selective, and precise to determine residue levels in all the matrices.

\section{Assessing the Risks}

The goal of the secondary hazard study is the assessment of risk associated with the secondary hazard. One commonly used approach is the EPA's risk quotient (RQ) 
Table I. Method Validation Results

\begin{tabular}{lcccc}
\hline \multicolumn{1}{c}{ Matrix } & $\begin{array}{c}\text { MLOD } \\
(\mu \mathrm{g} / \mathrm{g})\end{array}$ & $\begin{array}{c}\text { Validated } \\
\text { Range } \\
(\mu \mathrm{g} / \mathrm{g})\end{array}$ & $\begin{array}{c}\text { Mean } \\
\text { Recovery } \\
(\%)\end{array}$ & $\begin{array}{c}\text { Std. Dev. } \\
(\%)\end{array}$ \\
\hline Whole-body Rodent & 0.054 & $0.2-20$ & 89 & 6.7 \\
Dog Food & 0.085 & $0.1-2000$ & 89 & 11 \\
Ferret Liver & 0.091 & $0.2-200$ & 107 & 17 \\
Magpie Liver & 0.16 & $0.2-200$ & 107 & 15 \\
\hline
\end{tabular}

method (6). Generally, the RQ is defined as the ratio of the exposure dose or concentration to the dose or concentration expected to produce lethality in $50 \%$ of the population.

$$
R Q=\text { Exposure/Effects }
$$

$$
\mathrm{RQ}=\mathrm{Dose} / \mathrm{LD}_{50} \text { or } \mathrm{RQ}=\text { Concentration } / \mathrm{LC}_{50}
$$

Use of this method for risk assessment provides a way to weigh known effects versus expected exposure and provide a numerical basis for decision making. In the RQ method a value greater than 1 indicates that there are significant risks associated with the proposed use of this chemical. A RQ less than 1 indicates that the risks associated with the proposed use of this chemical may be acceptable under approved usage guidelines. This approach provides a conservative estimate of hazards as it assumes that $100 \%$ of the exposed animal's diet will consist of the pesticide formulation (primary hazard) or the tissue, organ, or carcass (secondary hazard) containing the highest concentration of residues. However, the RQ method is widely used and provides a ready framework for comparisons to other compounds. EPA further breaks down RQs of less than 1 into the following categories (7):

A RQ less than 0.1 represents a negligible risk. Values between 0.1 and 0.5 represent a moderate risk level. Finally, values greater than 0.5 represent a significant risk (7).

\section{Difethialone Study Results}

For the determination of residue levels in the carcasses of the primary species, twenty albino laboratory rats were feed a $0.0025 \%$ pelleted bait for three days $(n=10)$ or until death occurred $(n=10)$. The head, tail, feet, and pelt were removed from each
Table II. Risk Quotients and Associated Concerns

\begin{tabular}{cl}
\hline$R Q$ Value & \multicolumn{1}{c}{ Associated Risk } \\
\hline$<0.1$ & Use presents acceptable risk for use under approved guidelines \\
$>0.1$ & Use restrictions may be imposed to protect endangered species \\
$>0.2$ & $\begin{array}{l}\text { Use may be restricted to certified applicators and/or mitigation } \\
\text { techniques may be imposed }\end{array}$ \\
$>0.5$ & $\begin{array}{l}\text { Mitigation techniques will be imposed to protect all species of } \\
\text { the same taxonomic order }\end{array}$ \\
\hline
\end{tabular}

animal and the carcass was homogenized and analyzed for difethialone residues. There was no significant difference $(\mathrm{p} \leq 0.05)$ in the mean residue levels for the two groups. The average residue level was found to be $2.0 \mathrm{mg} / \mathrm{kg}$. (Range $=0.77-2.67$ $\mathrm{mg} / \mathrm{kg}, \mathrm{SD}=0.51$

The textbook definition of an $\mathrm{LD}_{50}$ typically involves a single, lethal dose being delivered to the test animal (1). However, as difethialone and other anticoagulant rodenticides are known to bioaccumulate, a gradual build-up to a lethal dose can occur. To better model this exposure scenario, a chronic method of determining the $\mathrm{LD}_{50}$ was used. For the estimation of chronic $\mathrm{LD}_{50}$ values ferrets and magpies were fed dog food fortified with difethialone at various concentrations. The amount of formulated dog food consumed was measured for each test animal each day and multiplied by the concentration of difethialone in the diet to give a value for the daily mass of difethialone ingested by each animal. Cumulative daily intakes were summed to yield a total dose ingested by each animal. The dose of toxicant was then divided by the individual animal weights to give a dose in $\mathrm{mg} / \mathrm{kg}$ of body weight which were, in turn, used to calculate $\mathrm{LD}_{50}$ values. The livers of these animals were assayed for difethialone residues to confirm exposure to difethialone. The mortality of these animals were recorded and, with the $\mathrm{mg} / \mathrm{kg}$ dose values, subjected to a probit analysis (8) to permit estimation of an $\mathrm{LD}_{50}$ value.

For magpies, the $\mathrm{LD}_{50}$ was estimated at approximately $4.7 \mathrm{mg} / \mathrm{kg}$. For ferrets, the $\mathrm{LD}_{50}$ was estimated at approximately $760 \mathrm{mg} / \mathrm{kg}$. The ferret $\mathrm{LD}_{50}$ estimate is less precise as there were only 2 ferrets per exposure level as compared to the magpie study, where 10 magpies were exposed to each difethialone concentration. For the ferret study, the variability is indicated by the fact that even though $100 \%$ mortality was observed at a difethialone concentration of $200 \mathrm{ppm}$, consistent $100 \%$ mortality was not observed for the ferrets fed higher toxicant concentrations. For both species, body weight, food consumption, difethialone concentration and mortality for each difethialone exposed animal was used to estimate the $\mathrm{LD}_{50}$.

$\mathrm{LC}_{50}$ values could have been used for the estimation of $\mathrm{RQ}$ values, however the 
$\mathrm{LD}_{50}$ value provides a more accurate assessment of toxicant exposure by using the daily food intake of each species. As food consumption rates may be quite different during a laboratory feeding study than under natural field conditions, we feel that the use of dose rather than concentration provides a more accurate assessment of toxicity and a more valid estimate of risk.

Using the daily food consumption formulas of Nagy (9) and the mean body weights for each species, the RQs for the primary hazards of difethialone were calculated according to the following formula:

$$
R Q=\frac{(\text { Food Intake } \times \text { Diet Concentration }) / \text { Body W eight }}{\mathrm{LD}_{50}}
$$

To demonstrate, the calculation of the RQ value for albino rodents feeding on the treated bait is calculated:

$$
R Q=\frac{(15.5 \mathrm{~g} / \mathrm{day} \times 25 \mathrm{mg} / \mathrm{kg}) / 300 \mathrm{~g}}{0.29 \mathrm{mg} / \mathrm{kg}}=4.45
$$

The RQ values for each species were calculated and the results are presented in Table III.

By comparing the RQ values listed in Table III with the concerns listed in Table II, the primary hazards associated with exposure to difethialone-treated baits can be estimated. As expected, the RQ value for the primary species feeding on the pelleted pesticide bait is significantly greater than 1.0 (Table III). Use of the estimated $\mathrm{LD}_{50}$ resulted in a RQ of 0.45 for the primary hazard of difethialone-treated baits to magpies. This suggests a moderate level of risk. However, this is surely an overestimate of the primary hazards to magpies as magpies are scavengers. It is very unlikely that magpies would directly consume difethialone baits intended for rodents. The primary hazards to magpies are likely minimal. This example illustrates the importance of considering the behavior of non-target species in addition to risk factors when estimating non-target hazards. Based on the RQ, the primary risk for

\section{Table III. Risk Quotients for Primary Hazards}

\begin{tabular}{lccc}
\hline \multicolumn{1}{c}{ Species } & $\begin{array}{r}\text { Mean Body } \\
\text { Weight }(g)\end{array}$ & $\begin{array}{c}\text { Food Intake } \\
(\text { g/day })\end{array}$ & $R Q$ \\
\hline Albino Rodents & 300 & 15.5 & 4.45 \\
European Ferrets & 530 & 40.8 & $<0.01$ \\
Black-billed Magpies & 160 & 13.6 & 0.45 \\
\hline
\end{tabular}

ferrets is also negligible. Even if a significant risk were generated for this species, this exposure scenario is just as unlikely for ferrets as it is for magpies. One important note is that the emphasis of the study was the estimation of secondary hazards. The fortified diet was designed to approximate secondary exposure via consumption of residue-containing carcasses. In a primary, non-target exposure scenario, the non-targets would consume the fortified bait. As the matrix may have an effect on the toxicity of a pesticide, these primary hazard estimates may be somewhat influenced by the matrix.

The RQ values for secondary hazards can be similarly determined by using the mean residue level of difethialone in the primary species as the diet for the secondary species. The values for the RQ are given in Table IV.

\section{Table IV. Risk Quotients for Secondary Hazards}

\begin{tabular}{lccc}
\hline \multicolumn{1}{c}{ Species } & $\begin{array}{r}\text { Mean Body } \\
\text { Weight }(g)\end{array}$ & $\begin{array}{c}\text { Food Intake } \\
(\text { g/day })\end{array}$ & $R Q$ \\
\hline European Ferrets & 530 & 40.8 & $<0.001$ \\
Black-billed Magpies & 160 & 13.6 & 0.036 \\
\hline
\end{tabular}

These results indicate that the secondary hazard for ferrets (mammalian scavengers) eating carcasses of the primary species are negligible. The secondary hazards for avian scavengers (magpies) are also negligible.

\section{Conclusions}

Design and implementation of a secondary hazard study involves many factors and considerations to ensure that valid estimates of risk are generated. These factors were presented and their consideration demonstrated through the use of a model pesticide, difethialone. If required, resulting risk estimates can be used to develop procedures to minimize undesirable non-target effects while maintaining efficacy.

\section{Acknowledgments}

Thanks go to Dennis Kohler, Tom Primus, and Doreen Griffin of the NWRC for sample analysis, method validation and quality control work on this project. 


\section{References}

1. Casarett and Doull's Toxicology: The Basic Science of Poisons-5th Edition; Klaassen, C. D.; Amdur, M. O.; Doull, J.; Eds.; McGraw-Hill: New York, 1996.

2. Lechevin, J.C.; Poché, R.M. Proc. Vertebr. Pest Conf. 1988, 13, 59-63.

3. Suter, G. In Ecological Risk Assessment; Suter, G.W. II, Ed.; Lewis: Chelsea, MI, 1993; Chapter 7.

4. Goldade, D.A.; Primus, T.M.; Johnston, J.J.; Zapien, D.C. J. Agric. Food Chem. 1998, 46, 504-508.

5. Goldade, D.A. M.S. Thesis, University of Colorado at Denver, 1997.

6. Urban, D.J.; Cook, N.J. Ecological Risk Assessment: Standard Evaluation Procedure of the Hazard Evaluation Division; U.S. Environmental Protection Agency. Office of Pesticide Programs. U.S. Government Printing Office: Washington, DC, 1986; EPA-540/9-85-001

7. National Research Council. Risk Assessment in Federal Government: Managing to Process; U.S. Government Printing Office: Washington, DC; NASNRC Publ. 1983.

8. SAS Operating System for Windows, Version 6.12 (1996). SAS Institute Inc. Cary, NC.

9. Nagy, K.A. Ecol. Monogr. 1987, 57, 111-128. 